\title{
Efficacy and safety of sitagliptin compared with sulfonylurea therapy in patients with type 2 diabetes showing inadequately controlled glycosylated hemoglobin with metformin monotherapy: A meta-analysis
}

\author{
LIQIONG HOU, TIEYUN ZHAO, YUNHUI LIU and YIYI ZHANG
}

\author{
Department of Endocrinology and Metabolism, West China Hospital of Sichuan University, \\ Chengdu, Sichuan 610000, P.R. China
}

Received June 18, 2014; Accepted January 26, 2015

DOI: $10.3892 /$ etm.2015.2277

\begin{abstract}
Previous randomized controlled trials (RCTs) have reported conflicting results for the efficacy of sitagliptin and sulfonylurea therapy in patients with type 2 diabetes mellitus showing inadequate glycemic control with metformin monotherapy. To clarify these findings, a meta-analysis was conducted of the outcomes of all published RCTs comparing sitagliptin with sulfonylureas in the treatment of type 2 diabetes mellitus. Standard medical databases were searched to identify relevant English- and Chinese-language RCTs. RCT results were compared regarding the mean change in glycated hemoglobin (HbAlc) level; the proportion achieving $<7 \%$ HbAlc; and a change in body weight. No significant differences were found between the metformin plus sitagliptin and metformin plus sulfonylurea groups regarding HbAlc or the proportion achieving $<7 \% \mathrm{HbAlc}$, while the metformin plus sitagliptin group experienced fewer hypoglycemic events $(\mathrm{P}<0.00001)$ and a greater reduction in body weight $(\mathrm{P}<0.00001)$. Metformin plus sitagliptin therapy may decrease HbAlc values in patients with type 2 diabetes mellitus who are not achieving their glycemic targets with metformin monotherapy in a manner similar to metformin plus sulfonylurea therapy, whilst posing a lower risk of hypoglycemia, and yielding a more beneficial effect on body weight.
\end{abstract}

\section{Introduction}

Type 2 diabetes mellitus has become a worldwide epidemic with a prevalence that has tripled in the last 30 years, and

Correspondence to: Professor Tieyun Zhao, Department of Endocrinology and Metabolism, West China Hospital of Sichuan University, 38 Guoxue Street, Wuhou, Chengdu, Sichuan 610000, P.R. China

E-mail: chuandazhaotieyun@163.com

Key words: diabetes mellitus, metformin, sitagliptin is predicted to affect $>350$ million individuals by 2025 (1). Despite lifestyle and pharmacological interventions, patients with type 2 diabetes mellitus continue to experience increases in glucose levels over time, which is likely to be as a consequence of declining $\beta$-cell function. One study found that approximately two-thirds of patients with type 2 diabetes mellitus in developed countries do not effectively control their glucose levels and that an even greater proportion does not do so in developing countries, particularly in China (2). A major reason for this failure is the progressive nature of type 2 diabetes mellitus, which makes it difficult for patients to maintain target levels of glycated hemoglobin (hemoglobin A1c; HbA1c) using traditional glucose-lowering agents, and usually requires them to take multiple antihyperglycemic agents (AHAs) to attain or maintain glycemic control.

Metformin, a commonly used oral antihyperglycemic agent used as a monotherapy and in combination with other antihyperglycemic agents, was introduced in the $1950 \mathrm{~s}$ for the treatment of type 2 diabetes mellitus. Metformin has many advantages, including that it neither promotes weight gain nor causes hypoglycemia, it exerts beneficial effects on cardiovascular risk (3) and is well tolerated and inexpensive (4). Due to these advantages, clinical practice guidelines (5-8) recommend metformin as the first-line oral antihyperglycemic drug for treating most patients with type 2 diabetes mellitus when glycemic control cannot be achieved by lifestyle interventions alone. Sulfonylureas are frequently used as a second-line therapy if the use of metformin alone does not achieve acceptable glycemic control (9); however, an increased risk of hypoglycemia and weight gain can result from sulfonylurea treatment (10). Newer treatment options and combination therapies that sustain glycemic control with fewer such adverse effects are, therefore, being evaluated. Sitagliptin, a dipeptidyl peptidase-4 (DPP-4) inhibitor, is an incretin-based therapy that is effective and well tolerated when used in addition to metformin therapy $(11,12)$. Furthermore, when added to metformin the risk of hypoglycemia with sitagliptin is similar to that observed using metformin with placebo (13). Several combination trials (14-19) have compared the efficacy and safety of 
sitagliptin with sulfonylurea therapy in patients with type 2 diabetes mellitus who are experiencing inadequate glycemic control (HbAlc $>6.5 \mathrm{mmol} / \mathrm{l}$ and $<10 \%$ ) on metformin monotherapy; however, the trials reported conflicting results and used modest sample sizes (15-18). To clarify these findings, in the current study a meta-analysis was conducted of all the published RCTs to compare the efficacy and safety of combined metformin and sitagliptin therapy with combined metformin and sulfonylurea therapy in patients with type 2 diabetes mellitus who had been experiencing inadequate glycemic control when treated with metformin monotherapy.

\section{Materials and methods}

Literature search. The Medline, Embase, Cochrane Library, Chinese National Knowledge Infrastructure and Chinese Biomedical Literature databases were systematically searched to identify studies published in English between January 2000 and December 2012 or published in Chinese between January 1996 and December 2012 using the following search terms: Type 2 diabetes mellitus, type II diabetes mellitus, diabetes mellitus type 2, metformin, sitagliptin, sulfonylurea, glibenclamide, gliclazide, glipizide controlled-release tablets, gliquidone, glimepiride, dipeptidyl peptidase-4 and clinical trial. Following retrieval of the relevant articles, a manual search of the references was performed to identify the relevant trials. Attempts were also made to contact investigators for unpublished data and the full text of articles when deemed necessary for clarification or for more information. Two investigators reviewed all potentially relevant articles independently to determine whether they met all the inclusion criteria and none of the exclusion criteria.

Study selection. Studies were included in the analysis if they met all the following inclusion criteria: i) Use of a prospective RCT; ii) comparison of combined metformin and sitagliptin therapy with combined metformin and sulfonylurea therapy in the treatment groups; iii) treatment of patients for $\geq 12$ weeks; iv) inclusion of patients who had not been achieving their glycemic targets with metformin monotherapy; and iv) reporting of outcomes in terms of HbAlc values. Trials were excluded if they met one or both of the following exclusion criteria: i) Evaluation of the addition of more than one drug to metformin monotherapy and/or ii) inclusion of participants using background therapies other than metformin monotherapy. Methodological quality assessment was conducted using the Cochrane Collaboration's tool for assessing the risk of bias in randomized trials. The RCTs were assessed for quality according to the criteria of i) method of randomization; ii) allocation concealment; iii) blinding of participants; iv) addressing of incomplete data; v) freedom of selective reporting; vi) comparability of groups at baseline; and vii) sample size calculation. The trials were independently reviewed and graded by two investigators who resolved any disagreements through discussion.

Outcome measures. The primary outcome measure was the mean change in HbA1c values from baseline to study endpoint. Secondary outcomes included the proportion of participants achieving $<7 \%$ HbAlc body weight, and the occurrence of hypoglycemia.

Data extraction. Two investigators independently reviewed the titles, abstracts and full texts of articles for inclusion using standardized data extraction forms. Validity assessment was performed using the Jadad scale (20). Disagreements were discussed between investigators until agreement had been achieved. The following data were extracted from each trial: i) An individual reference identifier which indicated author and publication year; ii) fundamental study data, including indication, treatment duration, number of patients randomized, treatment aims and background medication; iii) patient characteristics at baseline, including mean age, gender, ethnicity, duration of type 2 diabetes mellitus, body mass index and HbAlc values; iv) quality measures, including the means of random sequence generation, allocation concealment, blinding and efficacy analysis; the dropout rate; and the funding source(s); and v) endpoint values, including the mean change in HbAlc values; the number of patients achieving $<7 \%$ HbAlc; the change in body weight and the incidence of hypoglycemia.

Statistical analysis. The analyses were performed using Review Manager (version 5.0; The Cochrane Collaboration, Copenhagen, Denmark) and Stata (version 10; Stata Corp, College Station, TX, USA) software. The heterogeneity of treatment effects among the studies was formally tested with Cochrane's test at a significance level of $\mathrm{P}<0.1$ and determination of the $\mathrm{I}^{2}$ statistic, with $\mathrm{I}^{2}>50 \%$ considered an indication of significant heterogeneity between two trials. A random-effects model was used in the presence of heterogeneity and a fixed-effects model in the absence of heterogeneity. The weighted mean difference (WMD) or odds ratio and its $95 \%$ confidence interval (CI) for each outcome relative to the control were calculated for continuous and dichotomous variables, respectively. Studies were excluded from the meta-analysis if insufficient information was provided to enable standard error calculation.

\section{Results}

Study selection. The database search results are summarized in Fig. 1. Among the 33 full-text articles that were assessed for eligibility, six reported the results of six RCTs $(14-17,19,20)$ that fulfilled all the inclusion criteria and none of the exclusion criteria. The main reasons for the exclusion of six potential RCTs were the evaluation of the addition of more than one drug with metformin monotherapy, the inclusion of participants undergoing background therapies other than metformin, trial durations of $<12$ weeks, and a lack of participant randomization.

Study and patient characteristics. Table I summarizes the characteristics of the six RCTs and the 3,585 participants that they included. As can be observed, the mean patient age ranged from 53 to 59 years, the percentage of male patients from 48.3 to $62.9 \%$, and the baseline HbA1c level from 7.3 to $8.8 \%$.

Methodological quality and risk of bias. Table II shows the results of the assessment of risk of bias. As can be observed, the studies were found to be of moderate to high quality, 


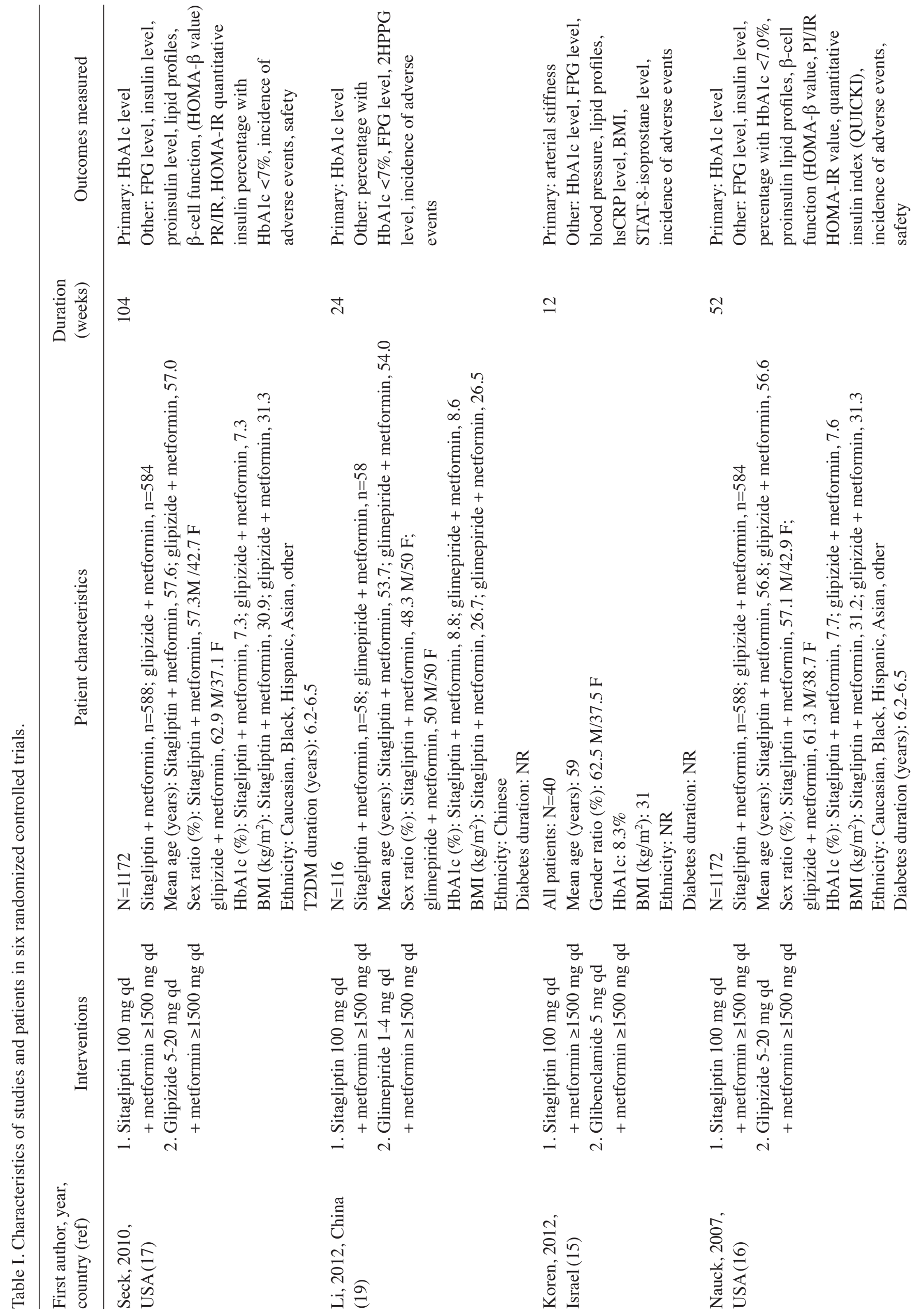




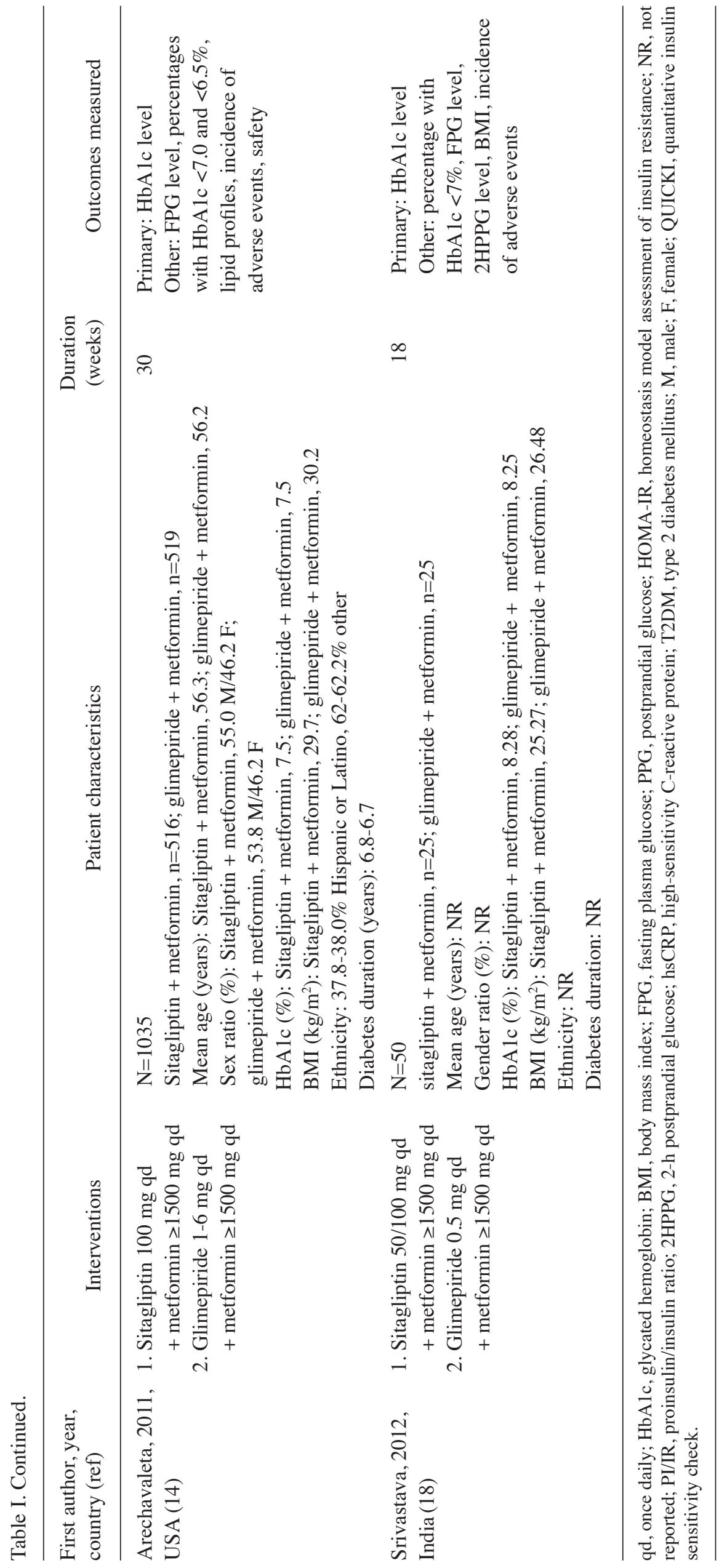


Table II. Results of quality assessment of six randomized controlled trials.

\begin{tabular}{|c|c|c|c|c|c|c|c|}
\hline $\begin{array}{l}\text { First author, } \\
\text { year (ref) }\end{array}$ & $\begin{array}{l}\text { Allocation } \\
\text { concealment }\end{array}$ & Blinding & Randomization & $\begin{array}{c}\text { Percentage } \\
\text { that completed } \\
\text { the trial }\end{array}$ & $\begin{array}{l}\text { Intention- } \\
\text { to-treat } \\
\text { analysis }\end{array}$ & $\begin{array}{l}\text { Free of } \\
\text { selective } \\
\text { reporting }\end{array}$ & $\begin{array}{c}\text { Groups } \\
\text { comparable } \\
\text { at baseline }\end{array}$ \\
\hline $\begin{array}{l}\text { Nauck, } 2007 \\
(16)\end{array}$ & Yes & $\begin{array}{l}\text { Yes, } \\
\text { double blind }\end{array}$ & $\begin{array}{l}\text { Computer-generated } \\
\text { allocation schedule }\end{array}$ & 68 & Yes & Yes & Yes \\
\hline $\begin{array}{l}\text { Arechavaleta, } \\
2011 \text { (14) }\end{array}$ & Yes & $\begin{array}{l}\text { Yes, } \\
\text { double blind }\end{array}$ & $\begin{array}{l}\text { Computer-generated } \\
\text { allocation schedule }\end{array}$ & 90 & Yes & Yes & Yes \\
\hline $\begin{array}{l}\text { Srivastava, } \\
2012(18)\end{array}$ & Unclear & Unclear & $\begin{array}{l}\text { Computer-generated } \\
\text { random number }\end{array}$ & 100 & No & Yes & Yes \\
\hline $\begin{array}{l}\text { Seck, } 2010 \\
\text { (17) }\end{array}$ & Yes & $\begin{array}{l}\text { Yes, } \\
\text { double blind }\end{array}$ & $\begin{array}{l}\text { Computer-generated } \\
\text { allocation schedule }\end{array}$ & 43 & Yes & Yes & Yes \\
\hline Li, 2012 (20) & Unclear & Unclear & Random number table & 100 & No & Yes & Yes \\
\hline $\begin{array}{l}\text { Koren, } 2012 \\
\text { (19) }\end{array}$ & No & $\begin{array}{l}\text { Open-label } \\
\text { crossover trial }\end{array}$ & Recruitment order & 85 & Yes & Yes & Yes \\
\hline
\end{tabular}

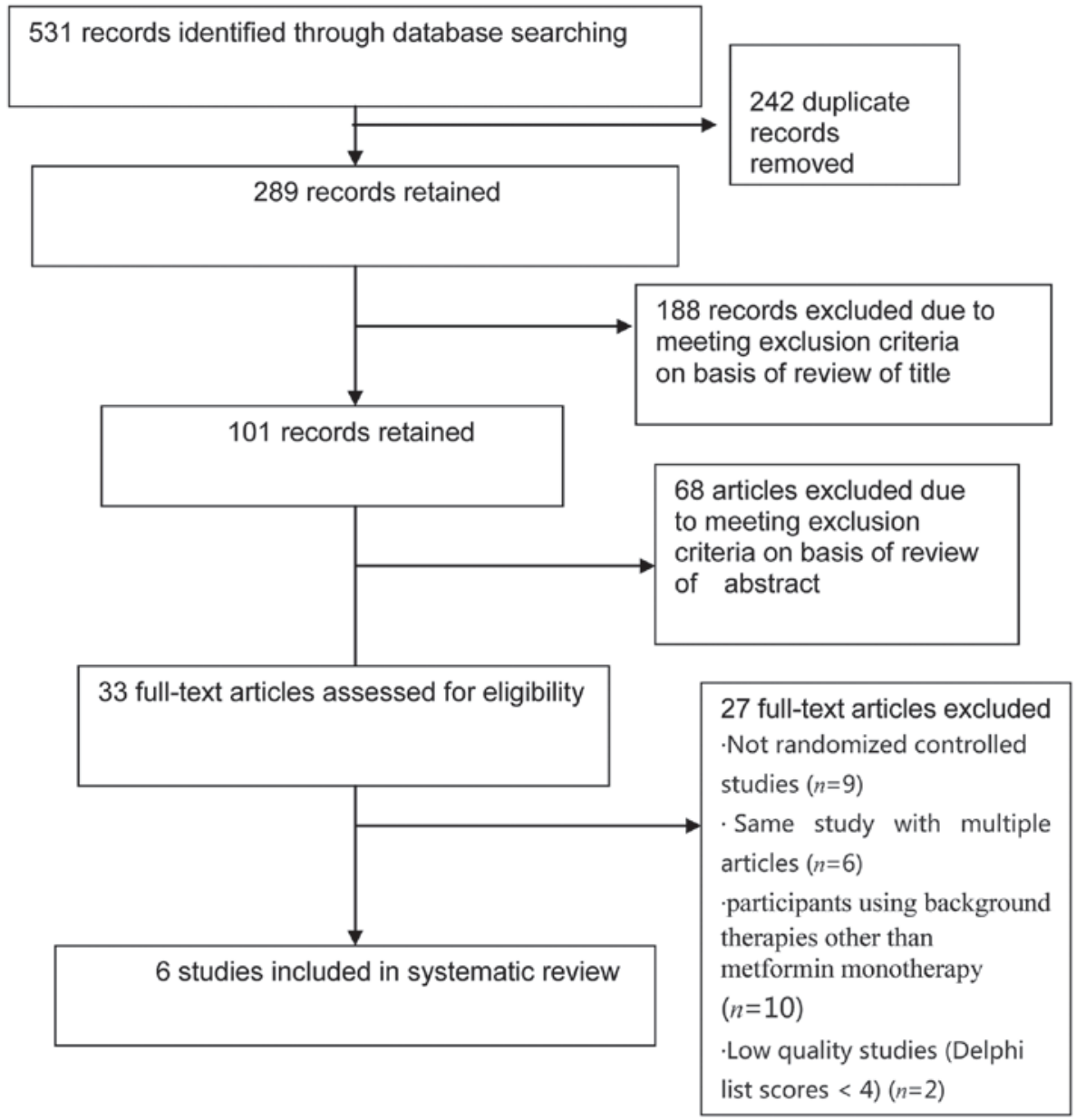

Figure 1. Flow chart of search results.

with the majority fulfilling five to seven of the seven quality criteria. Specifically, one study fulfilled three criteria, one study fulfilled five criteria and the remaining three studies fulfilled seven criteria. The use of blinding was not deemed practical in several RCTs.
Change in HbAlc values and HbAlc goal. Fig. 2 shows the results of the meta-analysis of the change in HbA1c from baseline (i.e., the effect estimate), the primary outcome of the six RCTs that reported a change in HbA1c for 2,410 subjects. As can be observed, no significant differences were found 


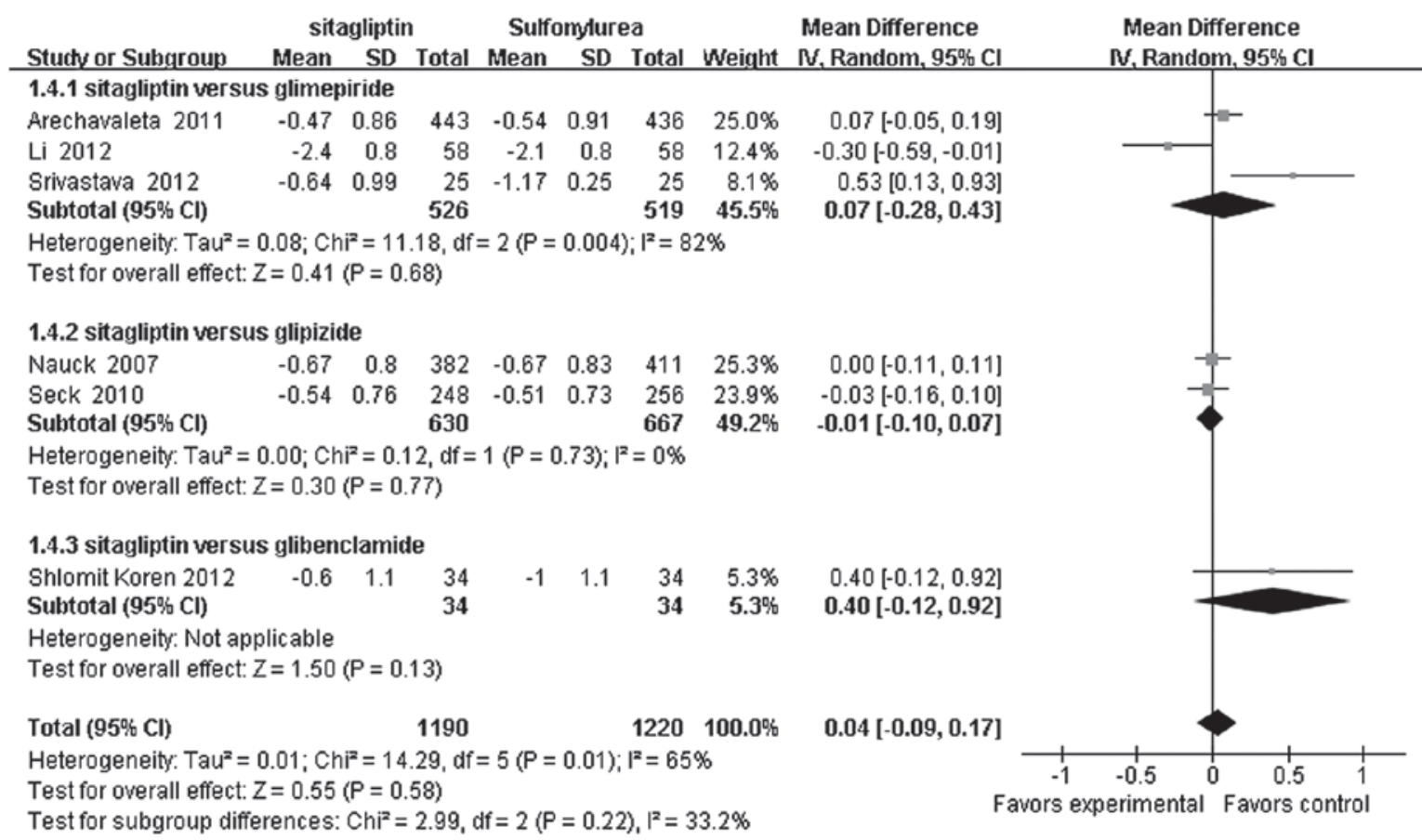

Figure 2. Comparison of changes in glycated hemoglobin between the metformin plus sitagliptin and the metformin plus sulfonylurea groups. SD, standard deviation; $\mathrm{CI}$, confidence interval; df, degrees of freedom.

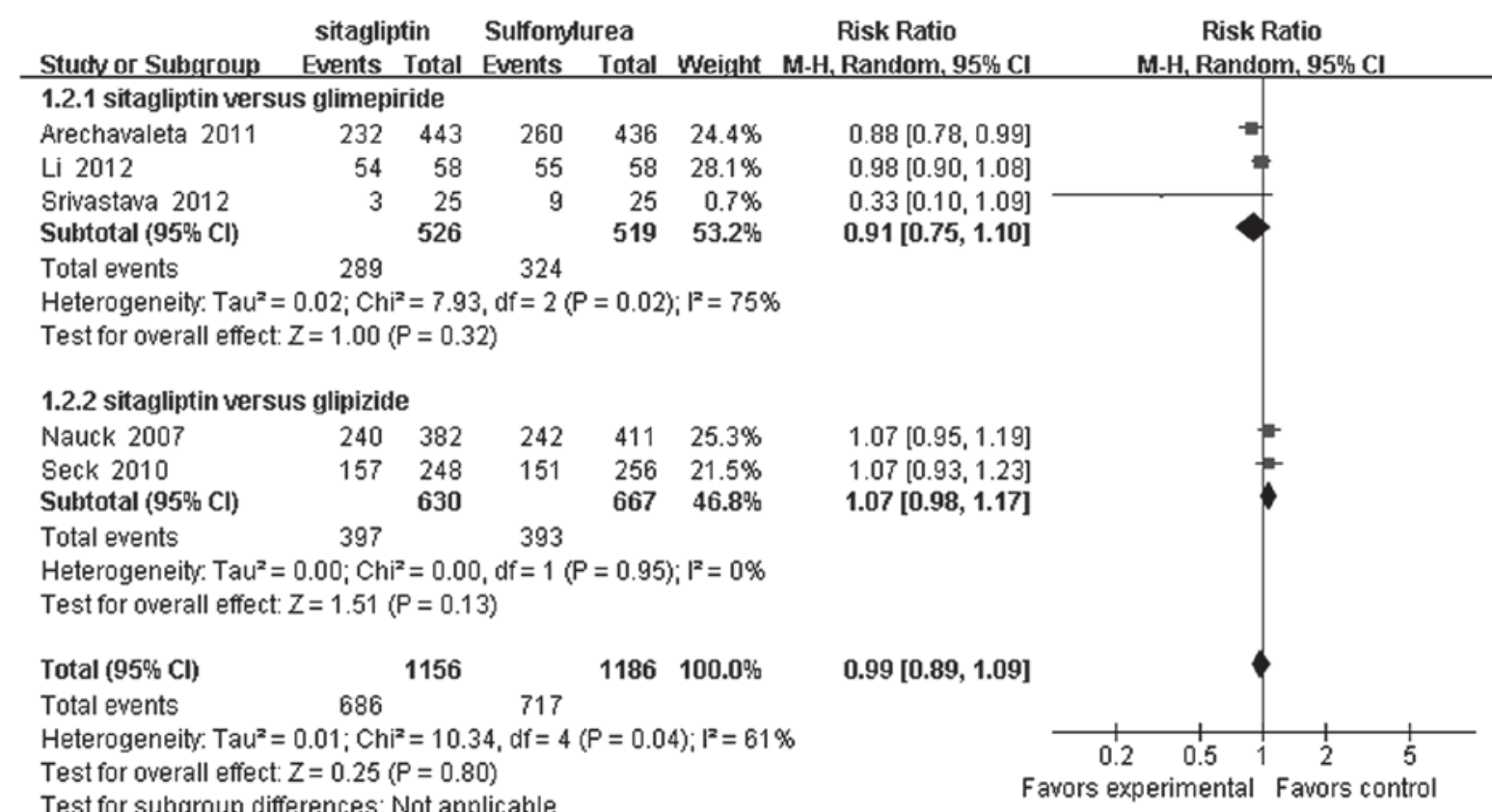

Figure 3. Comparison of achievements of $<7 \%$ glycated hemoglobin between the metformin plus sitagliptin and the metformin plus sulfonylurea groups. M-H, Mantel-Haenszel; CI, confidence interval.

between the metformin plus sitagliptin and the metformin plus sulfonylurea groups (WMD $=0.04,95 \% \mathrm{CI}-0.09$ to 0.17 , $\mathrm{P}=0.58)$. Fig. 3 shows the results of the meta-analysis of the risk ratio for achieving $<7 \% \mathrm{HbA} 1 \mathrm{c}$ for the five RCTs that reported the achievement of this goal for 2,342 subjects. As can be observed, no significant differences were found between the metformin plus sitagliptin and the metformin plus sulfonylurea groups in the attainment of this goal [risk ratio $(\mathrm{RR})=0.99,95 \%$ CI $0.89-1.09, \mathrm{P}=0.80]$.

Body weight. Fig. 4 shows the results of the meta-analysis of the change in body weight for the five trials that reported a change for 3,563 subjects. As can be observed, the metformin plus sitagliptin group was found to experience a significantly 


\begin{tabular}{|c|c|c|c|c|c|c|c|c|c|}
\hline \multirow[b]{2}{*}{ Stuchy or Subqroup } & \multicolumn{3}{|c|}{ sitagliptin } & \multicolumn{3}{|c|}{ Sulfomylurea } & \multirow[b]{2}{*}{ Weight } & \multirow{2}{*}{$\begin{array}{c}\text { Mean Difference } \\
\text { N. Fixed, } 95 \% \mathrm{Cl}\end{array}$} & \multirow{2}{*}{$\begin{array}{l}\text { Mean Difference } \\
\mathrm{N}, \text { Fixed, } 95 \% \mathrm{Cl}\end{array}$} \\
\hline & Mean & SD & Total & Mean & SD & Total & & & \\
\hline \multicolumn{10}{|c|}{ 1.5.1 Sitagliptin versus glimepiride } \\
\hline Arechavaleta 2011 & -0.8 & 3.48 & 516 & 1.2 & 3.49 & 519 & $4.4 \%$ & $-2.00[-2.42,-1.58]$ & - \\
\hline Li 2012 & -1.2 & 0.3 & 58 & 0.6 & 0.2 & 58 & $92.6 \%$ & $-1.80[-1.89,-1.71]$ & \\
\hline Subtotal $(95 \% \mathrm{Cl})$ & & & 574 & & & 577 & $97.0 \%$ & $-1.81[-1.90,-1.72]$ & 1 \\
\hline \multicolumn{10}{|c|}{ Heterogeneity: $\mathrm{Chi}^{2}=0.81, \mathrm{df}=1(P=0.37) ;\left.\right|^{2}=0 \%$} \\
\hline \multicolumn{10}{|c|}{ Test for overall effect: $Z=39.11(P<0.00001)$} \\
\hline \multicolumn{10}{|c|}{ 1.5.2 Sitagliptin versus glipizide } \\
\hline Nauck 2007 & -1.5 & 6.78 & 588 & 1.1 & 6.78 & 584 & $1.3 \%$ & $-2.60[-3.38,-1.82]$ & $\longrightarrow$ \\
\hline Seck 2010 & -1.6 & 8.04 & 588 & 0.7 & 8.01 & 584 & $0.9 \%$ & $-2.30[-3.22,-1.38]$ & 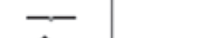 \\
\hline Subtotal $(95 \% \mathrm{Cl})$ & & & 1176 & & & 1168 & $2.3 \%$ & $-2.48[-3.07,-1.88]$ & \\
\hline \multirow{2}{*}{\multicolumn{10}{|c|}{$\begin{array}{l}\text { Heterogeneity: } \mathrm{Chi}^{2}=0.24, d f=1(P=0.62) ;\left.\right|^{2}=0 \% \\
\text { Test for overall effect } \mathrm{Z}=8.18(P<0.00001)\end{array}$}} \\
\hline & & & & & & & & & \\
\hline \multicolumn{10}{|c|}{ 1.5.3 sitagliptin versus glibenclamide } \\
\hline Shlomit Koren 2012 & -0.2 & 2 & 34 & 1.2 & 2.3 & 34 & $0.8 \%$ & $-1.40[-2.42,-0.38]$ & - \\
\hline Subtotal $(95 \% \mathrm{Cl})$ & & & 34 & & & 34 & $0.8 \%$ & $-1.40[-2.42,-0.38]$ & \\
\hline \multicolumn{10}{|c|}{ Heterogeneity: Not applicable } \\
\hline \multicolumn{10}{|c|}{ Test for overall effect: $Z=2.68(P=0.007)$} \\
\hline Total $(95 \% \mathrm{Cl})$ & & & 1784 & & & 1779 & $100.0 \%$ & $-1.82[-1.91,-1.73]$ & 1 \\
\hline $\begin{array}{l}\text { Heterogeneity. } \mathrm{Chi}^{2}= \\
\text { Test for overall effect. }\end{array}$ & $\begin{array}{l}\text { 3.44, df }= \\
=39.98\end{array}$ & $\begin{array}{l}=4(P= \\
3(P<C\end{array}$ & $\begin{array}{l}=0.17) ; \\
0.00001\end{array}$ & $l^{2}=38$ & & & & & $\begin{array}{llll}4 & -2 & 0 & 2\end{array}$ \\
\hline
\end{tabular}

Figure 4. Comparison of changes in body weight between the metformin plus sitagliptin and the metformin plus sulfonylurea groups. SD, standard deviation; CI, confidence interval.

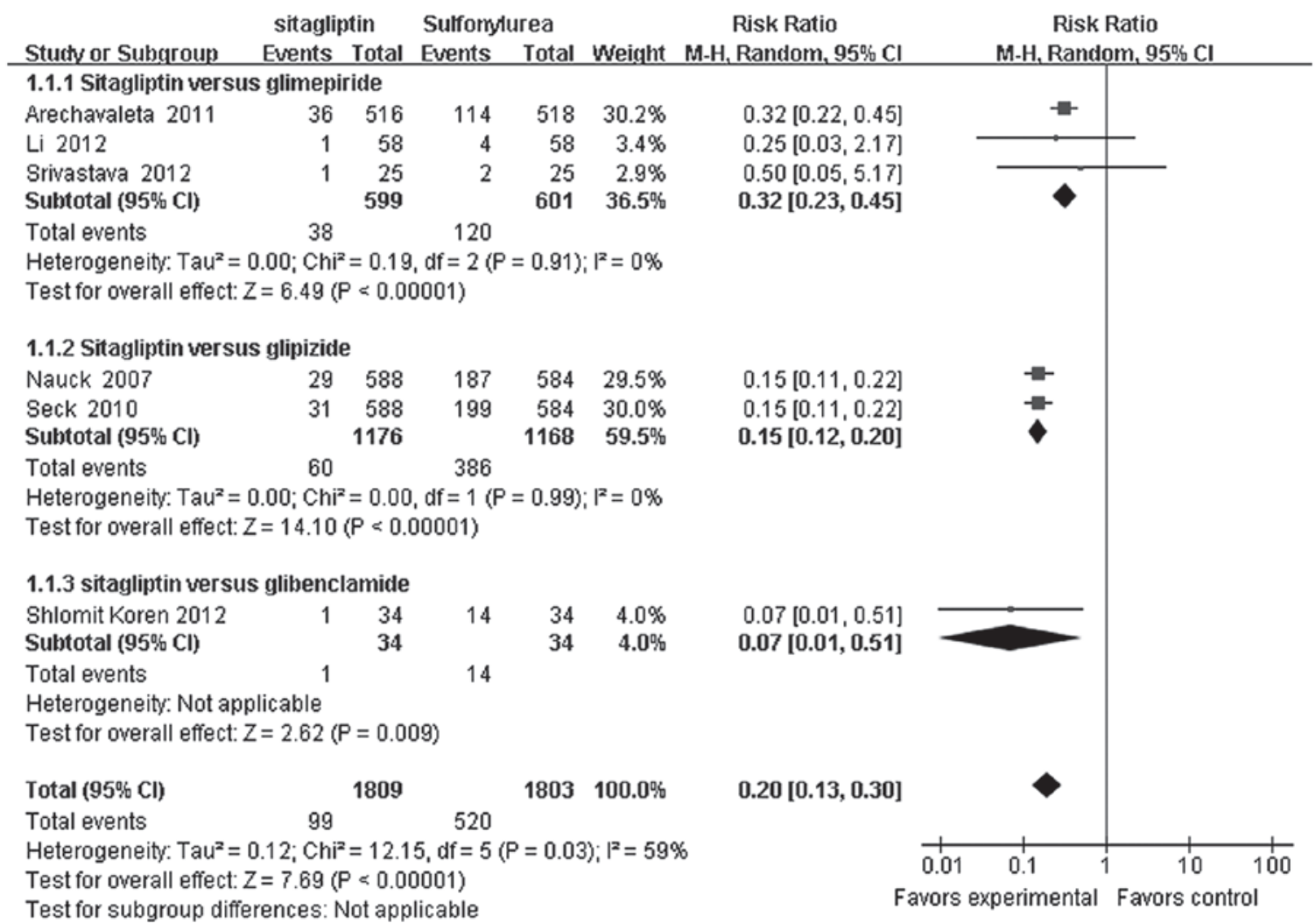

Figure 5. Comparison of occurrence of hypoglycemic events between the metformin plus sitagliptin and the metformin plus sulfonylurea groups. M-H, Mantel-Haenszel; CI, confidence interval.

greater loss in body weight compared with the metformin plus sulfonylurea group (WMD=-1.82; $95 \% \mathrm{CI},-1.91$ to -1.73 ; $\mathrm{P}<0.00001)$.
Hypoglycemic events. Fig. 5 shows the results of the meta-analysis of the six RCTs that reported that 3,612 patients had experienced at least one hypoglycemic event. As can be 
observed, the metformin plus sitagliptin group was found to experience significantly fewer hypoglycemic events compared with the metformin plus sulfonylurea group $(\mathrm{R} R=0.20$; 95\% CI, 0.13-0.30; P<0.00001).

\section{Discussion}

The results of the meta-analyses conducted in this study strongly indicate that the addition of sitagliptin therapy to the regimen of patients with type 2 diabetes mellitus who are currently undergoing metformin monotherapy but failing to achieve their glycemic targets can result in a reduction in HbAlc values similar to that resulting from the addition of sulfonylurea therapy to metformin monotherapy. Metformin plus sulfonylurea therapy, however, was not found to lower the risk of hypoglycemia to the same extent as metformin plus sitagliptin therapy. Since sulfonylurea stimulation of insulin secretion is not strictly glucose dependent (21), sulfonylurea agents continue to stimulate insulin secretion even with falling glucose concentrations (22). By contrast, sitagliptin inhibits the enzymatic degradation and inactivation of glucagon-like peptide-1 (GLP-1), thus increasing endogenous GLP-1 and gastric inhibitory polypeptide levels $(23,24)$. GLP-1 then potentially stimulates insulin secretion and inhibits glucagon release effects that disappear when glucose levels approach normal concentrations (25). Sitagliptin also induces stimulation of insulin release and the suppression of glucagon release in a glucose-dependent fashion.

The results also suggest that metformin plus sitagliptin therapy results in greater weight loss compared with metformin plus sulfonylurea therapy. Regarding the underlying mechanism, sitagliptin can increase endogenous GLP-1, which, by delaying gastric-emptying, increases satiety, resulting in significant weight loss (26). This beneficial effect is important, as weight gain is a common side effect of sulfonylurea treatment that may be related to a sulfonylurea-induced increase in insulin concentrations (27).

The present study had two primary strengths and three major limitations that should be considered when reviewing the results. Regarding its strengths, the study authors ensured that only high-quality evidence was examined by limiting the inclusion of studies to only double-blind RCTs. Furthermore, as the first systematic review, to the best of our knowledge, to compare the efficacy and safety of sitagliptin and sulfonylurea therapies in the treatment of patients with type 2 diabetes mellitus experiencing inadequate glycemic control with metformin monotherapy, this study filled an important research gap. Regarding its limitations, the study examined RCTs that were conducted for varying lengths of time (range, 12-104 weeks), which may affect the extent to which the results can be compared. In addition, as the RCTs did not report economic indicators, the present study was not able conduct the relevant economic analysis. Such analysis is important, as cost is a significant consideration in therapeutic decision making in order to support the allocation of sufficient healthcare resources for the treatment of type 2 diabetes mellitus and its complications, particularly in light of its increasing global prevalence. Finally, as none of the RCTs were designed to compare the cardiovascular endpoints of the two study groups, any conclusions regarding outcomes, such as cardiovascular morbidity or mortality, should be considered with caution and only be accepted following confirmation by additional investigation by more RCTs.

In conclusion, the addition of sitagliptin therapy to the regimen of patients with type 2 diabetes mellitus who are not achieving their glycemic targets with metformin monotherapy may result in a reduction in HbAlc values in a manner similar to the addition of sulfonylurea therapy to metformin monotherapy while posing a lower risk of hypoglycemia and resulting in a greater loss of weight.

\section{Acknowledgements}

This study was supported by the Department of Endocrinology and Metabolism, West China Hospital of Sichuan University, which offered a grant for a literature review.

\section{References}

1. Stulc $\mathrm{T}$ and Sedo A: Inhibition of multifunctional dipeptidyl peptidase-IV: is there a risk of oncological and immunological adverse effects? Diabetes Res Clin Pract 88: 125-131, 2010.

2. Choudhury SR, Datta A, Chanda S, et al: Overview of current and upcoming strategies implied for the therapy of type 2 diabetes mellitus. Curr Diabetes Rev 10: 275-282, 2014.

3. Eurich DT, McAlister FA, Blackburn DF, et al: Benefits and harms of antidiabetic agents in patients with diabetes and heart failure: systematic review. BMJ 335: 497, 2007.

4. Saenz A, Fernandez-Esteban I, Mataix A, et al: Metformin monotherapy for type 2 diabetes mellitus. Cochrane Database Syst Rev 3: CD002966, 2005.

5. IDF Clinical Guidelines Task Force: Global Guideline for Type 2 Diabetes: recommendations for standard, comprehensive, and minimal care. Diabet Med 23: 579-593, 2006.

6. National Collaborating Centre for Chronic Conditions (UK): Type 2 Diabetes: National Clinical Guideline for Management in Primary and Secondary Care (Update). National Institute for Health and Clinical Excellence: Guidance. Royal College of Physicians, London, 2008.

7. American Diabetes Association: Standards of medical care in diabetes - 2009. Diabetes Care 32 (Suppl 1): S13-S61, 2009.

8. American Diabetes Association: Standards of medical care in diabetes - 2010. Diabetes Care 33 (Suppl 1): S11-S61, 2010.

9. Nathan DM, Buse JB, Davidson MB, et al; American Diabetes Association and the European Association for Study of Diabetes: Medical management of hyperglycemia in type 2 diabetes: a consensus algorithm for the initiation and adjustment of therapy: a consensus statement of the American Diabetes Association and the European Association for the Study of Diabetes. Diabetes Care 32: 193-203, 2009

10. Inzucchi SE: Oral antihyperglycemic therapy for type 2 diabetes: scientific review. JAMA 287: 360-372, 2002.

11. Goldstein BJ, Feinglos MN, Lunceford JK, et al; Sitagliptin 036 Study Group: Effect of initial combination therapy with sitagliptin, a dipeptidyl peptidase-4 inhibitor, and metformin on glycemic control in patients with type 2 diabetes. Diabetes Care 30: 1979-1987, 2007.

12. Charbonnel B, Karasik A, Liu J, et al; Sitagliptin Study 020 Group: Efficacy and safety of the dipeptidyl peptidase- 4 inhibitor sitagliptin added to ongoing metformin therapy in patients with type 2 diabetes inadequately controlled with metformin alone. Diabetes Care 29: 2638-2643, 2006.

13. Williams-Herman D, Johnson J, Teng R, et al: Efficacy and safety of initial combination therapy with sitagliptin and metformin in patients with type 2 diabetes: a 54-week study. Curr Med Res Opin 25: 569-583, 2009.

14. Arechavaleta R, Seck T, Chen Y, et al: Efficacy and safety of treatment with sitagliptin or glimepiride in patients with type 2 diabetes inadequately controlled on metformin monotherapy: a randomized, double-blind, non-inferiority trial. Diabetes Obes Metab 13: 160-168, 2011.

15. Koren S, Shemesh-Bar L, Tirosh A, et al: The effect of sitagliptin versus glibenclamide on arterial stiffness, blood pressure, lipids, and inflammation in type 2 diabetes mellitus patients. Diabetes Technol Ther 14: 561-567, 2012. 
16. Nauck MA, Meininger G, Sheng D, et al; Sitagliptin Study 024 Group: Efficacy and safety of the dipeptidyl peptidase-4 inhibitor, sitagliptin, compared with the sulfonylurea, glipizide, in patients with type 2 diabetes inadequately controlled on metformin alone: a randomized, double-blind, non-inferiority trial. Diabetes Obes Metab 9: 194-205, 2007.

17. Seck T, Nauck M, Sheng D, et al; Sitagliptin Study 024 Group: Safety and efficacy of treatment with sitagliptin or glipizide in patients with type 2 diabetes inadequately controlled on metformin: a 2-year study. Int J Clin Pract 64: 562-576, 2010.

18. Srivastava S, Saxena GN, Keshwani P and Gupta R: Comparing the efficacy and safety profile of sitagliptin versus glimepiride in patients of type 2 diabetes mellitus inadequately controlled with metformin alone. J Assoc Physicians India 60: 27-30, 2012.

19. Li WH, Lin M and Zhang XJ: Comparison on adding sitagliptin or glimepiride in poorly controlled overweight type 2 diabetes with oral metformin. Zhongguo Yi Yuan Yao Xue Za Zhi 32: 792-794, 2012 (In Chinese)

20. Higgins JPT and Altman DG: Assessing risk of bias in included studies. In: Cochrane Handbook for Systematic Reviews of Interventions. Higgins JPT and Green S (eds). John Wilry \& Sons, Chichester, pp187-241, 2008.
21. DeFronzo RA: Pharmacologic therapy for type 2 diabetes mellitus. Ann Intern Med 131: 281-303, 1999.

22. Inzucchi SE: Oral antihyperglycemic therapy for type 2 diabetes: scientific review. JAMA 287: 360-372, 2002.

23. Bergman AJ, Stevens C, Zhou Y, et al: Pharmacokinetic and pharmacodynamic properties of multiple oral doses of sitagliptin, a dipeptidyl peptidase-IV inhibitor: a double-blind, randomized, placebo-controlled study in healthy male volunteers. Clin Ther 28: 55-72, 2006.

24. Herman GA, Stevens C, Van Dyck K, et al: Pharmacokinetics and pharmacodynamics of sitagliptin, an inhibitor of dipeptidyl peptidase IV, in healthy subjects: results from two randomized, double-blind, placebo-controlled studies with single oral doses. Clin Pharmacol Ther 78: 675-688, 2005.

25. Maedler K, Carr RD, Bosco D, et al: Sulfonylurea induced beta-cell apoptosis in cultured human islets. J Clin Endocrinol Metab 90: 501-506, 2005.

26. Drucker DJ: Enhancing incretin action for the treatment of type 2 diabetes. Diabetes Care 26: 2929-2940, 2003.

27. Krentz AJ and Bailey CJ: Oral antidiabetic agents: current role in type 2 diabetes mellitus. Drugs 65: 385-411, 2005. 